\title{
In-patient care facilities for old people in Austria: commentaries from a spatial-research perspective.
}

\author{
Tatjana Fischer* \\ Institute of Spatial Planning, Environmental Planning and Land Rearrangement (IRUB), University of Natural \\ Resources and Life Sciences, Vienna, Peter-Jordan-Straße 82, 1190 Vienna/Austria
}

Keywords: Dementia, Nursing, Spatial, Reliability.

Accepted on February 05, 2018

\section{Introduction}

The agreement between the Federal Government and its provinces on common measures for people in need of care [1] considers spatial-related aspects with regard to choice location and nationwide provision. In this context, terms such as "central" and "local" are used.

Nonetheless, there is an ongoing public debate on the quality of life in nursing homes (related to the quality of care). Besides suffering from the bad image of their working places, the nursing staff faces growing pressure caused by the necessity to perform entertainment tasks due to the lack of the support from the residents' family members.

Against the backdrop of the increasing number of in-patient care facilities for old people in Austria-2014 nursing and residential homes had a total of approximately 80.000 beds [2]there is an urgent need for discussing the relevance of locationbased factors for maintaining a decent life for those who work and live in in-patient care facilities in order to better integrate nursing and residential homes into their location communities and to realize strategies and mission statements such as "caring communities" [3], "dementia-friendly municipalities" [4] or "integrated care for the elderly" [5].

\section{State-of-the-Art Knowledge Concerning Spatial- Related Aspects of In-patient Facilities in Austria}

In 2016 the author of this article conducted a non-funded pilot study on the spatial-related characteristics of all 889 in-patient care facilities in Austria. For this purpose, all verbal information basing on estimations and judgements of nursing home administrations-published in three volumes "Residential and Nursing Homes in Austria" (BMASK 2014) edited by the Austrian Federal Ministry of Labour, Social Affairs and Consumer Protection-was analysed using content analysis and taking into account the "degree of urbanization" according to the European Commission defined by population density (Eurostat undated) [6].

The findings have been published for the first time in the proceedings of WMCAUS 2017, the $2^{\text {nd }}$ World Multidisciplinary Civil Engineering-Architecture-Urban Planning Symposium, held in Prague, June 2017 [3]. In the following, the key results are summarized: Location, infrastructure \& green areas, and community integration-each comprising various spatial-related characteristics and aspects, amongst others accessibility, reachability, and stakeholders-are used to describe the present situation (in order to promote an in-patient care facility) and the future plans.

Related to the location characteristics it was discovered that centrality matters. Centrality within location municipality and leisure facilities in close proximity obviously matter in (small) towns/suburbs and rural areas.

Spatial-related requirements depend on nursing orientation and population density. In-patient care facilities in urban settings benefit from "good" infrastructure provision within walking distance in contrast to those in rural settings. This may be the reason for the minor importance of community integration for residential homes in the "city context". Furthermore, the main focus of an in-patient care facility determines the different relevance of infrastructural facilities, respectively the relevance of volunteers.

The future plans reflect (spatial) planning-related concerns, wishes and worries of the nursing home administrations. In this context, two specific aims are stressed: better integration within the location municipalities and strengthening of volunteering.

\section{Recommendations for Research Agenda Setting}

It has been shown that the consideration of spatial-related aspects is essential for debating quality of life in in-patient care facilities for old people.

Due to the fact that the accuracy of the provided verbal information has not yet been checked, it is necessary to assess their reliability in order to enable a comprehensive inter- and transdisciplinary discussion on crucial questions of location planning, amongst others: Is there a (fundamental) link between the level of the community integration of a facility and the spatial conditions of the location municipality?.

Are in-patient facilities for long-time care, located in infrastructurally weak and ageing (rural) municipalities, appropriate for becoming a hub of everyday consumer services (such as hairdressers, beauty salons and cafes?).

For this purpose, first of all in-patient care facilities must be understood as final main residences of elderly dependents (not as health facilities). Based on this general understanding, we have to find out more about the logic and dynamic forces (actors, networks) behind stationary long-term care location planning. In order to achieve this, the (spatial) planning disciplines can bring an important contribution. 
Citation: Fischer T. In-patient care facilities for old people in Austria: commentaries from a spatial-research perspective. J Intensive Crit Care Nurs. 2018;1(1):2-3

\section{References}

1. Republic of Austria: Agreement between the Federal Government and its provinces in accordance with Article 15a B-VG on common measures for people in need of care, together with Annexes. 1993; StF: BGBl. Nr. 866.

2. Fischer T. Nursing Homes and their Spatial ContextsFindings from Austria. IOP Conf Ser Mater Sci Eng. 2017;245:1-10.

3. Smith-Campbell B. A case study on expanding the concept of caring from individuals to communities. Public Health Nurs. 1999;16(6):405-11.

4. Alzheimer's Disease International (ADI) (Ed.). Dementia Friendly Communities. Global Developments, 2nd Edition, London, September 2017.

5. World Health Organization (WHO) (Ed.). Integrated care for older people: guidelines on community-level interventions to manage declines in intrinsic capacity. Geneva 2017.

6. Eurostat. The Degree of urbanization (DEGURBA).

\section{*Correspondence to:}

Tatjana Fischer

Institute of Spatial Planning,

Environmental Planning and

Land Rearrangement

University of Natural Resources and

Life Sciences,

Vienna. Peter-Jordan-Straße 82,

1190 Vienna/Austria

E-mail: tatjana.fischer@boku.ac.at 